\title{
Piomiositis en niños. Reporte de 2 casos
}

\author{
Felipe Cavagnaro, Jaime Rodríguez, M. Eugenia Arancibia, Bárbara Walker y Aníbal Espinoza
}

\section{Pyomyositis in children. Report of two cases}

Pyomyositis (PM) is an uncommon pyogenic infection of skeletal muscle and, when not properly treated, it can progress to a high-risk clinical situation with high mortality. Because it usually has a subacute presentation, diagnosis is often delayed. We present two cases of PM of the paraspinal muscles in healthy children and discuss the current state of knowledge of this disease.

Key words: Pyomyositis, Staphylococcus aureus, bacteremia, musculoskeletal infection.

Palabras clave: Piomiositis, Staphylococcus aureus, bacteriemia, infección musculo esquelética.

\section{Introducción}

$\mathrm{L}$ a piomiositis $(\mathrm{PM})$ es una infección supurativa subaguda poco frecuente del músculo estriado. Fue inicialmente descrita por Scriba en 1885 , en pacientes que vivían en áreas tropicales, por lo que esta enfermedad fue inicialmente conocida como "piomiositis tropical". En las últimas décadas se han descrito numerosos casos de PM en climas templados, especialmente en personas adultas con enfermedades crónicas y/o con compromiso inmunológico ${ }^{2}$. Si bien puede afectar a todos los grupos etarios, se observa con mayor frecuencia en la primera y segunda década de la vida, afectando mayoritariamente a los varones ${ }^{2,3}$. Debido a su baja frecuencia en nuestro medio y a su presentación clínica usualmente poco específica, especialmente cuando el músculo afectado no es superficial, esta patología es muchas veces errónea o tardíamente diagnosticada ${ }^{3,4}$.

La importancia de un correcto diagnóstico de la PM radica en que puede retrasar un correcto tratamiento médico-quirúrgico, con consecuencias ocasionalmente invalidantes y eventualmente fatales ${ }^{3,4}$.

Existe escasa información en relación a la ocurrencia de esta patología en nuestro país ${ }^{5}$. Describimos a continuación dos casos de niños previamente sanos con diagnóstico demostrado de PM primaria y se revisa el estado actual del conocimiento de esta enfermedad.

\section{Caso 1}

Varón de 11 años, previamente sano, quien consultó en el Servicio de Urgencia (S.U.) pediátrico por un cuadro febril hasta $38,5^{\circ} \mathrm{C}$ axilar durante tres días, asociado a moderado dolor abdominal difuso. No había antecedentes de traumatismos ni de viajes recientes al extranjero. En el examen físico general sólo destacaba la palpación de deposiciones de consistencia aumentada en el abdomen. Se le administró un enema rectal dando salida a deposiciones normales y fue citado para reevaluación en $24 \mathrm{~h}$. El paciente siguió febril, agregándose vómitos frecuentes. En una nueva evaluación, la temperatura era $39,2^{\circ} \mathrm{C}$ axilar, estaba taquicárdico y taquipneico, presión arterial $85 / 55 \mathrm{mmHg}$, bien hidratado, no encontrándose nuevos hallazgos en el examen físico. Principales hallazgos de laboratorio: hemograma con recuento de leucocitos de $15.500 / \mathrm{mm}^{3}$, (neutrófilos $82,5 \%$, baciliformes $2 \%$ ), hemoglobina $13,7 \mathrm{~g} / \mathrm{dL}$, velocidad de eritrosedimentación (VHS) $2 \mathrm{~mm} / \mathrm{h}$, proteína C reactiva (PCR) 4,89 mg/dL (valor normal $<1 \mathrm{mg} / \mathrm{dL}$ ). La ecografía abdominal fue informada como normal. Se diagnosticó una gastroenteritis aguda indicándosele control ambulatorio. $\mathrm{Al} 5^{\circ}$ día de evolución seguía febril, con tránsito digestivo normal pero con dolor abdominal de tipo cólico. Consultó nuevamente en el S.U., donde se repitieron exámenes de laboratorio: hemograma con recuento de leucocitos de 7.400/ $\mathrm{mm}^{3}$ (baciliformes 4\%), VHS $29 \mathrm{~mm} / \mathrm{h}$ y PCR 16,6 mg/dL. Una nueva ecografía abdominal evidenció la presencia de adenopatías mesentéricas y contenido ecogénico (floculaciones) intravesical. Los análisis de orina completa, inmunocromatografía para Streptocococcus pyogenes faríngeo, estudio de virus respiratorios por inmunofluorescencia (virus respiratorio sincicial, adenovirus, influenza A-B, parainfluenza 1,2,3 y metapneumovirus) y reacción de Widal fueron negativos. El paciente fue internado con el diagnóstico de síndrome febril de foco desconocido. Se solicitaron hemocultivos (2) y urocultivo, sin iniciar antibioterapia. Evolucionó febril y más decaído en las horas siguientes, apareciendo un dolor intenso en la zona dorso lumbar bilateral que le impedía incorporarse de posición supina a sedestación, sin focalizar el sitio doloroso específico y sin rubor o tumoración del área sensible. Se inició terapia con cloxacilina y cefotaxima i.v. por sospecha de espondilitis séptica. Los estudios con
Clínica Alemana de Santiago, Chile.

Servicio de Pediatría (JR, BW). Servicio de Radiología (AE). Clínica Alemana-Universidad del Desarrollo, Santiago, Chile. Facultad de Medicina (FC, MEA)

Recibido: 5 de marzo de 2012 Aceptado: 30 de noviembre de 2012

Correspondencia a: Felipe Cavagnaro fcavagnaro@alemana.cl 
Figura 1A . Corte axial de RM a nivel L1, secuencias T2. Leve aumento de la intensidad de la señal en musculatura paravertebral izquierda (flecha).

Figura 1B. Ecografía de la musculatura paravertebral izquierda. Se observa discreta alteración de la ecotextura muscular. radiografía de tórax y ecocardiografía fueron normales. Una resonancia magnética (RM) de columna lumbosacra detectó signos inflamatorios en la musculatura paravertebral posterior parasagital izquierda desde T10 hasta L3, sin colecciones evidentes (Figura 1A). La ecografía dirigida a la zona dolorosa identificó mínimos cambios en la ecogenicidad y leve hiperemia al Doppler color de la musculatura paravertebral lumbar derecha, hallazgos considerados inespecíficos (Figura 1B).

El hemocultivo resultó positivo para Staphylococcus aureus sensible a cloxacilina, por lo que se suspendió la cefotaxima. El urocultivo fue negativo y el cintigrama óseo Tc 99m MDP fue normal.

Luego de $48 \mathrm{~h}$ de tratamiento antibacteriano se observó un descenso de la curva febril y del dolor dorso-lumbar, la PCR cayó a $6,6 \mathrm{mg} / \mathrm{dL}$ el $6^{\circ}$ día y a $3,1 \mathrm{mg} / \mathrm{dL}$ el $8^{\circ}$ día de hospitalización. Se dio de alta en buenas condiciones generales al $10^{\circ}$ día de antibioterapia con cefadroxilo, luego de estar una semana afebril.

\section{Caso 2}

Niña de 10 años, previamente sana, quien consultó en el S.U. pediátrico por dolor lumbar hacía cuatro días, luego de realizar deportes acuáticos de manera intensa. Posteriormente se agregó impotencia para deambular.
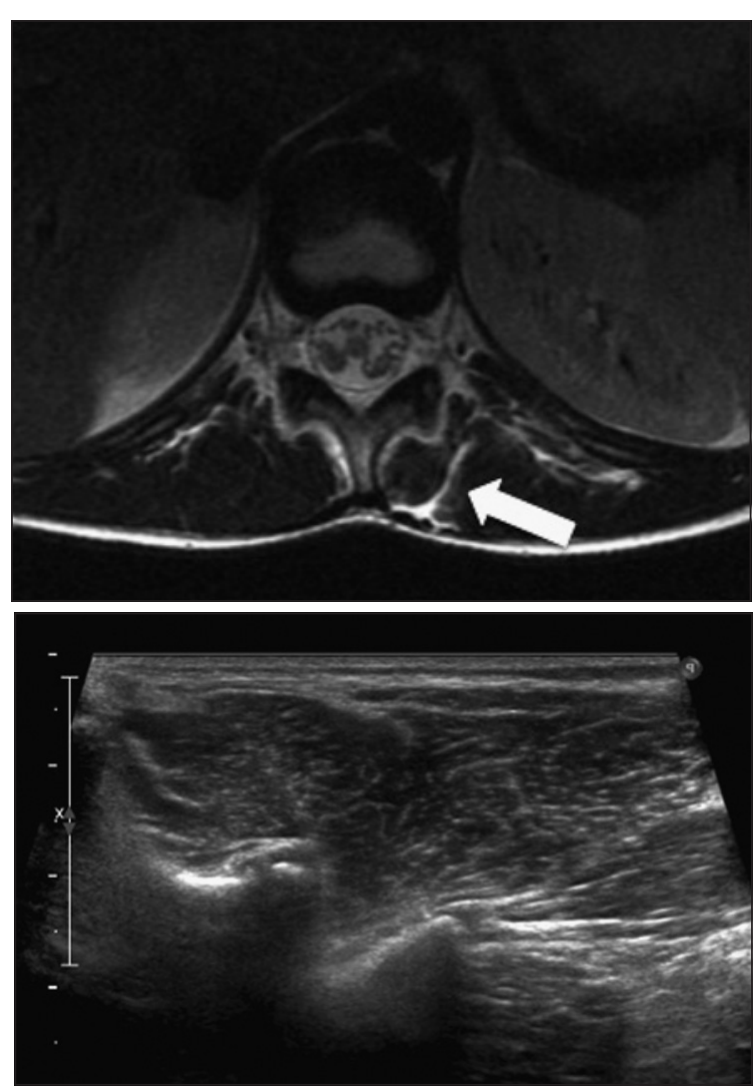

No tenía antecedentes recientes de viajes al extranjero, traumatismos directos, ni heridas. A las $48 \mathrm{~h}$ de iniciarse el dolor se agregó fiebre de $39^{\circ} \mathrm{C}$, dolor hipogástrico y lumbar, asociado a dificultad en la marcha y compromiso del estado general. No presentaba vómitos, diarrea ni disuria.

Fue hospitalizada con sospecha de una espondilitis séptica. En el examen físico destacaba una temperatura axilar de $38,8^{\circ} \mathrm{C}$, marcado dolor a la palpación de la zona lumbar derecha, sin signos inflamatorios en la piel de esa zona ni adenopatías regionales. Exámenes de laboratorio destacables: hemograma con recuento de leucocitos de $9.400 / \mathrm{mm}^{3}$ (neutrófilos $78 \%$, baciliformes $2 \%$ ), hemoglobina 14,9 g/dL, VHS 16 mm/h y PCR 6,1 mg/dL, orina completa normal.

La ecografía abdominal evidenció linfonodos mesentéricos levemente aumentados de tamaño, de aspecto inespecíficos. Se inició tratamiento empírico con cloxacilina y cefotaxima i.v. luego de obtener hemocultivos (2) y urocultivo. Una RM de columna lumbosacra demostró un extenso edema de la musculatura paravertebral, de predominio derecho, extendiéndose desde L1 hasta la región sacra, más localizado entre L4 y S1 a izquierda, y la presencia de una pequeña colección interespinosa entre L4-L5, lateralizada a derecha, de hasta $17 \mathrm{~mm}$ de diámetro (Figuras 2A-B). Una ecografía concomitante de tejidos blandos demostró la presencia de una colección hipoecogénica, mal delimitada, polilobulada de 1,5 x 0,9 $\mathrm{cm}$, con importante edema de la grasa adyacente (Figura 2C). Un hemocultivo fue positivo para $S$. aureus sensible a cloxacilina, suspendiéndose la cefotaxima. Se completó el estudio de focos secundarios con ecocardiografía, radiografía de tórax y cintigrafía ósea, los que resultaron normales. El urocultivo fue negativo y la creatinquinasa fue de $88 \mathrm{U} / \mathrm{L}$ (valor normal 25-177 U/L). Al tercer día de hospitalización inició descenso de la curva febril, la PCR descendió a 7,8 mg/dL y luego a 3,7 mg/dL (día 5) y 1,3 $\mathrm{mg} / \mathrm{dL}$ (día 7) de hospitalización, fecha en que fue dado de alta en buenas condiciones para continuar antibioterapia ambulatoria con cefadroxilo, completando tres semanas en total. Una ecografía dorso-lumbar de control al egreso no mostraba colecciones intramusculares.

\section{Discusión}

La PM es considerada una infección de adolescentes $\mathrm{y}$ adultos jóvenes aunque puede comprometer a todos los grupos etarios incluso lactantes, con predomino en el sexo masculino ${ }^{2,3}$. No existen datos claros de su incidencia y prevalencia. Bickels y cols., encontraron 679 casos en la literatura médica de habla inglesa entre 1960 y $2002^{3}$. La PM se clasifica como primaria cuando se produce por diseminación hematógena sin un foco o puerta de entrada, como ocurrió en nuestros dos casos, o secundaria cuando se produce por infección de un sitio adyacente, como piel, 


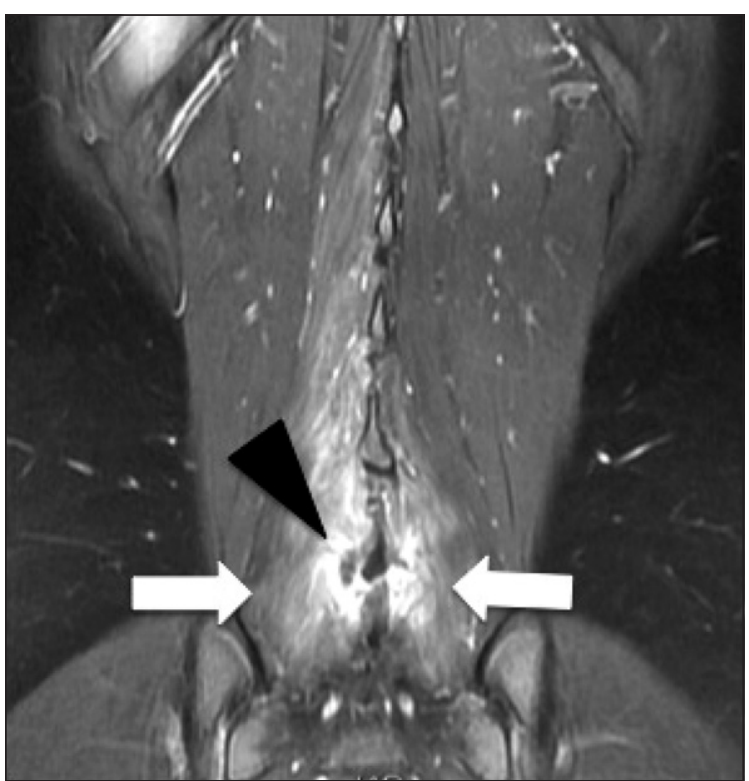

Figura 2A. RM secuencia T1 con gadolinio, corte coronal mostrando extenso edema de la musculatura paravertebral bilateral de predominio derecho desde L1 al sacro (flechas). Se observa además pequeña colección lateralizada a derecha (cabeza de flecha).

hueso o tejidos blandos, incluyendo vísceras huecas ${ }^{3,4}$. La diferenciación entre tropical y no tropical parece no tener importancia actualmente dada la ausencia de diferencias clínicas significativas entre ambas entidades ${ }^{3,6}$. La PM primaria puede comprometer cualquier músculo o grupo muscular, o ser multifocal hasta en $20 \%$ de los casos. En general, los músculos de los miembros inferiores y tronco son los más afectados ${ }^{3,6,7}$. Llamativamente, $\mathrm{y}$ a diferencia de nuestros dos casos presentados, el compromiso de músculos paraespinales parece ser inhabitual en niños ${ }^{8}$. El agente etiológico más frecuentemente aislado, como ocurrió en nuestros pacientes, es $S$. aureus, con una frecuencia de $95 \%$ en climas tropicales y $70 \%$ en climas templados, independiente del estado inmunológico del paciente. Estudios efectuados en la década del '70 con fagotipificación no lograron identificar una cepa predominante en el mundo como causante de piomiositis . Streptococcus pyogenes puede ser causa de piomiositis, pero de evolución habitualmente fulminante y grave, con formación de abscesos o necrosis muscular, y/o con compromiso de varios paquetes musculares ${ }^{6}$. En pacientes con compromiso inmunológico pueden aislarse Escherichia coli, Yersinia enterocolitica, Klebsiella spp, Salmonella spp, especies anaeróbicas estrictas, hongos o micobacterias $^{2,3,10}$. La etiopatogenia de la PM primaria no está aclarada. Se ha planteado la hipótesis que ocurriría luego de una bacteriemia transitoria, usualmente sin un foco inicial conocido ${ }^{3,7}$. Esta bacteriemia aislada parece no ser suficiente para infectar un músculo "sano", ya
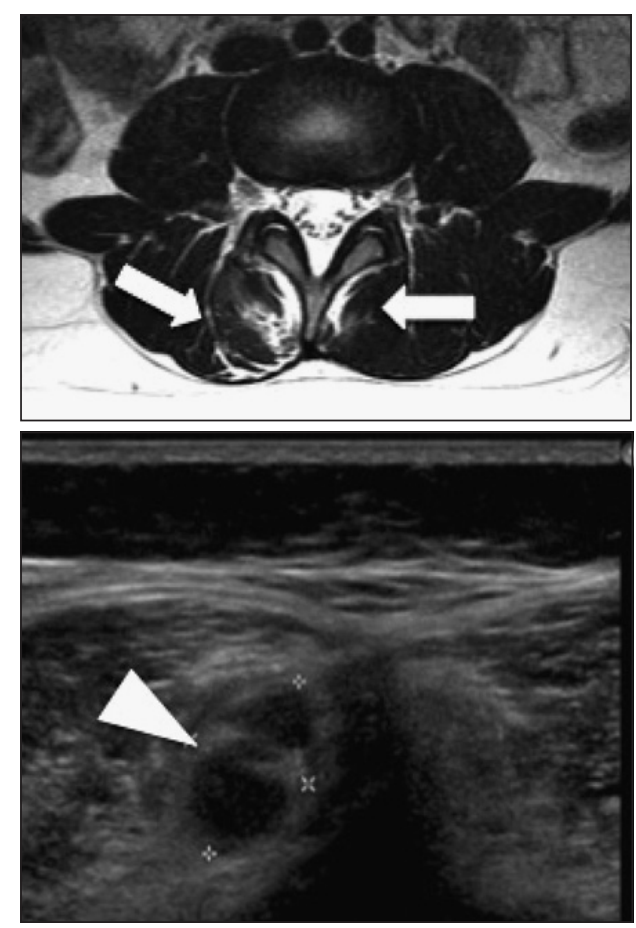

Figura 2B. RM secuencia T2 en corte axial lumbar mostrando importante edema de la musculatura paravertebral bilateral (flechas).

Figura 2C. Ecografía de musculatura lumbar que muestra una colección intramuscular mal delimitada paravertebral derecha (cabeza de flecha), con importante edema de la grasa adyacente. que los abscesos musculares son muy poco frecuentes en pacientes fallecidos por septicemia estafilocóccica ${ }^{11}$. En modelos experimentales con animales, la inyección intravenosa de $S$. aureus produjo abscesos en el hígado, riñón y bazo, sin comprometer músculos sanos, pero, luego de dañar músculos con golpes eléctricos o punciones mecánicas $48 \mathrm{~h}$ antes de la inoculación de la bacteria, se desarrollaron abscesos en los músculos dañados hasta en $50 \%$ de los animales, entre 2 y 28 días después, no encontrándose infección en los músculos no traumatizados $^{12}$. El trauma muscular previo ha sido propuesto como un claro coadyuvante para desarrollar una PM, si bien sólo 25 a $50 \%$ de los pacientes tienen ese dato ${ }^{2}$. Bajo este concepto también debe pensarse en ejercicios extenuantes, convulsiones, golpes eléctricos y miositis virales o parasitarias ${ }^{2,3}$. Es importante considerar que el trauma muscular puede haber ocurrido hasta un par de semanas antes de comenzar los síntomas ${ }^{3}$. En nuestros pacientes, no hubo un claro antecedente de trauma, y sólo en el segundo caso se obtuvo el antecedente de ejercicios extenuantes en los días anteriores. Además, los pacientes con PM debieran ser investigados por un eventual uso de drogas i.v, patologías crónicas y compromiso inmunológico, especialmente virus de inmunodeficiencia humana en individuos mayores ${ }^{2,3,13}$ (Tabla 1).

La expresión clínica de esta enfermedad depende mucho del estadío de evolución en que se detecta (Tabla 2), pero puede ir desde un cuadro de dolor muscular con o sin impotencia funcional y fiebre, hasta un estado séptico 


Tabla 1. Factores de riesgo de piomiositis
Daño muscular
Traumático
Miositis virales o parasitarias
Ejercicios intensos
Convulsiones
Compromiso inmunológico
Infección por VIH
Leucemia aguda, anemia aplástica
Agammaglobulinemia
Diabetes mellitus
Uso de corticoesteroides
Enfermedades autoinmunes
Otras neutropenias e inmunodeficiencias
Mixtas
Déficit nutricional
Uso de drogas intravenosas
Enfermedades crónicas avanzadas
Alcoholismo

Tabla 2. Estadios de la piomiositis

\begin{tabular}{|c|c|c|c|}
\hline Estadio & Síntomas & Examen físico & Laboratorio \\
\hline 1. Etapa invasora & $\begin{array}{l}\text { Fiebre baja, malestar } \\
\text { general, calambres } \\
\text { dolorosos, dolor local }\end{array}$ & $\begin{array}{l}\text { Músculo moderadamente } \\
\text { indurado en palpación } \\
\text { profunda, sin eritema ni } \\
\text { calor local }\end{array}$ & Leucocitosis ocasional \\
\hline 2. Etapa supurativa & $\begin{array}{l}\text { Aumento del dolor, } \\
\text { con mayor inflamación } \\
\text { local }\end{array}$ & $\begin{array}{l}\text { Eritema, aumento de volu- } \\
\text { men y sensibilidad localiza- } \\
\text { da, formación de abscesos }\end{array}$ & $\begin{array}{l}\text { Leucocitosis, aumento } \\
\text { de reactantes de fase } \\
\text { aguda }\end{array}$ \\
\hline $\begin{array}{l}\text { 3. Etapa tardía o } \\
\text { séptica }\end{array}$ & $\begin{array}{l}\text { Fiebre alta y dolor } \\
\text { intenso }\end{array}$ & $\begin{array}{l}\text { Manifestaciones sistémicas, } \\
\text { incluyendo shock séptico. } \\
\text { Músculo puede estar fluc- } \\
\text { tuante. }\end{array}$ & $\begin{array}{l}\text { Bacteriemia, } \\
\text { complicaciones }\end{array}$ \\
\hline
\end{tabular}

Tabla 3. Diagnóstico diferencial de la piomiositis

Trombosis venosa profunda
Tromboflebitis
Osteomielitis aguda
Artritis séptica
Espondilitis aguda
Celulitis
Fascitis necrosante
Hematoma, desgarro muscular
Sarcoma
Apendicitis, peritonitis

con alta letalidad ${ }^{7,14}$. La lesión es habitualmente dolorosa a la palpación, bien delimitada e indurada, pero el eritema y edema cutáneo son infrecuentes debido a lo profundo de la localización. Usualmente su diagnóstico es tardío, dada la baja sospecha clínica, aunque los pacientes suelen consultar en promedio luego de 5 a 6 días de iniciado sus síntomas ${ }^{7,10}$. En nuestros dos pacientes, la primera consulta ocurrió al $3^{\circ}$ y $4^{\circ}$ día de sintomatología. Como es de suponer, el diagnóstico diferencial está muy relacionado al cuadro clínico observado y al grupo muscular comprometido (Tabla 3). En nuestros dos casos, uno de ellos fue admitido con diagnóstico de síndrome febril sin foco y el otro como espondilitis séptica. Tal vez la relativa precocidad en establecer el diagnóstico de PM e iniciar tratamiento antimicrobiano en nuestros pacientes permitió que, al menos en el primer caso, no haya habido el tiempo suficiente para la formación de colecciones supuradas intramusculares.

Los estudios de laboratorios son inespecíficos pero orientadores a una infección bacteriana, mostrando leucocitosis con forma inmaduras, elevada VHS y altos valores de $\mathrm{PCR}^{2,3,10}$. Los valores séricos de enzimas musculares son generalmente normales, lo que ayuda a descartar una miositis de otras etiologías ${ }^{3}$. Los hemocultivos son positivos hasta en 10\% en casos de PM "tropicales" y $35 \%$ en climas templados ${ }^{2}$. En nuestros casos, ambos tuvieron hemocultivos positivos.

Con la sospecha clínica se debe enfocar un juicioso estudio de imágenes. El método de elección en esta patología es la RM, pues demuestra, con alta fidelidad, la extensión y el compromiso muscular inflamatorio difuso, y la eventual abscedación ${ }^{3,10}$. La ecografía puede mostrar etapas más avanzadas de la enfermedad, con aumento de volumen muscular, alteración de la ecotextura y lesiones hipoecogénicas, ocasionalmente con contenido líquido; la incorporación del efecto Doppler a esta técnica puede aumentar la certeza diagnóstica ${ }^{3,10}$. La tomografía computada puede mostrar cambios similares a los descritos en la ecografía y aporta en esclarecer el compromiso óseo pero, a diferencia de la RM, falla en detectar cambios inflamatorios difusos precoces, especialmente en niños con escasa grasa corporal, lo que hace más difícil diferenciar entre estructuras de tejidos blandos ${ }^{3,10}$. Dado que la etiopatogenia sospechada está relacionada a bacteriemias, se debe incluir en el estudio de imágenes una ecocardiografía en busca del compromiso de válvulas cardíacas y eventualmente, un cintigrama óseo para documentar el compromiso óseo tardío ${ }^{2}$. En nuestros pacientes ambos estudios fueron normales.

El tratamiento de este cuadro está muy relacionado al estadio en que se encuentra la enfermedad al momento de la confirmación diagnóstica. Durante etapas precoces, luego de ser internado el paciente, se deben iniciar antibioterapia según la epidemiología local para estos procesos 
y el estado inmunológico del paciente. En pacientes inmunocompetentes, la terapia inicial debiera estar dirigida contra $S$. aureus y S. pyogenes ${ }^{2,7}$. Se prefiere el uso de una penicilina semisintética resistente a $\beta$-lactamasas como cloxacilina, nafcilina u oxacilina, o una cefalosporina de primera generación. En caso de pacientes con antecedentes de alergia a penicilina puede optarse por el uso de clindamicina. En el concierto internacional se ha reportado una creciente incidencia de infecciones por $S$. aureus resistente a cloxacilina (convencionalmente meticilinaSARM) ${ }^{15}$, especialmente en infecciones graves de piel y tejidos blandos. Estos reportes han incluido también a América del Sur ${ }^{14}$. Frente a la sospecha epidemiológica o demostración de SARM, es indicación de usar vancomicina o clindamicina ${ }^{2,16}$. En pacientes inmunocomprometidos la cobertura antimicrobiana se debe ampliar a bacilos gramnegativos y anaerobios estrictos. La duración del tratamiento antimicrobiano debe ajustarse a la evolución clínica y radiológica. En pacientes sin complicaciones, tres a seis semanas de terapia parecen ser suficientes, la primera de ellas parenteral y el resto por vía oral, ajustado según sensibilidad in vitro ${ }^{2,3,10}$. Antes de suspender la antibioterapia, es recomendable controlar los valores de PCR y VHS. La formación de un absceso exige un apropiado drenaje (percutáneo o a cielo abierto) y desbridamiento de los tejidos afectados, enviando siempre muestras a cultivo.

El tratamiento adecuado lleva a la recuperación completa del paciente en la mayoría de los casos pero se han comunicado complicaciones como osteomielitis del hueso adyacente, debilidad muscular, impotencia funcional, cicatrices musculares y deformación estética localizada, e incluso una mortalidad de $10 \%$ en el período agudo ${ }^{3,17}$.

\section{Conclusión}

La PM es una condición patológica infrecuente en niños y de difícil diagnóstico precoz, dado lo inespecífico del cuadro clínico inicial. Puede comprometer cualquier músculo o grupo muscular, aunque predomina su localización en las extremidades inferiores y cintura pélvica. Entre los principales antecedentes a averiguar están las posibles puertas de entrada o foco infeccioso, el trauma muscular y las situaciones que deriven en compromiso inmunológico. El examen de elección para su diagnóstico es la RM, aunque puede ser detectado en fases más tardías con ecografía y tomografía computada. El tratamiento depende del estadio en que se encuentre la enfermedad, recomendándose en forma inicial el uso de terapia anti-estafilocóccica y estreptocóccica por vía parenteral, y el drenaje de colecciones si las hubiere. Dado el potencial bacteriémico de la PM, se deben descartar otras focalizaciones de la infección, tales como óseas y en válvulas cardíacas.

\section{Resumen}

La piomiositis (PM) es una infección piógena infrecuente del músculo estriado y, cuando no es tratada adecuadamente, puede evolucionar hasta una situación clínica de alto riesgo vital. Debido a su presentación usualmente subaguda, el diagnóstico es a menudo tardío. Presentamos dos casos clínicos de PM de la musculatura paraespinal en escolares sanos y se describe el estado actual del conocimiento de esta enfermedad.

\section{Referencias bibliográficas}

1.- Scriba J. Beitrag zur aetiologie der myositis acuta. Dtsch Z Chir 1885; 22: 497-502.

2.- Baddour L, Keerasuntornpong A. Pyomyositis. En: Up to date 19.3, Sexton D (Ed.), Waltham, MA, 2011.

3.- Bickels J, Ben-Sira L, Kessler A, Wientroub S. Primary pyomyositis. J Bone Joint Surg 2002; 84-A: 2277-86.

4.- Taksande A, Vilhekar K, Gupta S. Primary pyomyositis in a child. Int J Infect Dis 2009; 13; e 149 -e 151.

5.- Arriagada D, Donoso A. Piomiositis del músculo piriforme. Rev Esp Cir Ortop Traumat 2011; 55: 50-3

6.- Barret A, Gresham G. Acute streptococcal myositis. Lancet 1958; 1: 347-51.

7.- Villamil-Cajoto I, Maceiras-Pan F, VillaciánVicedo M J. Piomiositis: presentación de 17 casos en niños y adultos. Rev Med Chile 2006; 134: 31-8.

8.- Hassan F, Shannak A. Primary pyomyositis of the paraspinal muscles: a case report and literature review. Eur Spine J 2008; 17 (Suppl 2): S239-S242.

9.- Grose C. Staphylococcal pyomyositis in South Texas. J Pediatr 1978; 93: 457-8.

10.- Mitsionis G, Manoudis G, Lykissas M, Sionti I, Motsis E, Gerogoulis A, et al. Pyomyositis in children: early diagnosis and treatment. J Ped Surg 2009; 44: 2173-8.

11.- Smith I M, Vickers A B. Natural history of 338 treated and untreated patients with staphylococcal septicaemia (1936-1955). Lancet 1960; 1: 1318-22.

12.- Miyake H. Beitrage zur kenntnis der sogenannten myositis infectiosa. Mitt Grenageb Med Chir 1904; 13:155-98.

13.- Gubbay A, Issacs D. Pyomiositis in children.
Pediatr. Infect Dis J 2000; 19:1009-12.

14.- Block A, Marshall C, Ratcliffe A, Athan W. Staphylococcal pyomyositis ina temperate region: epidemiology and modern management. MJA 2008; 189: 323-5.

15.- Eady A, Cove J. Staphylococcal resistance revisited: community acquired methicillin resistant Staphylococcus aureus - an emerging problem for the management of skin and soft tissue infections. Curr Opin Infect Dis 2003; 16 : 103-24

16.- Jozefkowics M, Jorrat P, Méndez J. Piomiositis primaria por Staphylococcus aureus meticilinoresistente proveniente de la comunidad. Arch Argent Pediatr 2008; 106: 533-51.

17.- Sharma A, Kumar S, Wanchu A, Sharma K, Sharma N, Singh R, et al.Clinical characteristics and predictors of mortality in 67 patientes with primery pyomyositis; a study from North India. Clin Rheumatol 2010; 29: 45-51. 